\title{
Encaminhamento do paciente crítico para UTI por decisão judicial: situações vivenciadas pelos enfermeiros
}

Aceito para publicação em julho de 2010

\author{
Alessandra Ceci dos Santos ${ }^{1}$ \\ Mara Ambrosina de Oliveira Vargas ${ }^{2}$ \\ Nadir Schneider ${ }^{3}$
}

Pesquisa qualitativa, exploratória e descritiva que busca explicar as situações vivenciadas pelos enfermeiros relacionadas ao encaminhamento de paciente para internação na UTI por decisão judicial. Projeto aprovado pelo Comitê de Ética e Pesquisa da Unisinos. Verifica-se que os enfermeiros, em sua maioria, estão assumindo seu papel com cidadania e orientando os familiares a procurar ajuda junto ao Ministério Público, a fim de viabilizar ao paciente grave um leito de UTI.

Descritores: Assistência à Saúde, Internação Hospitalar, Unidade de Terapia Intensiva, Ética.

\section{Referral of critical patient to ICU by judicial decision: situations experienced by nurses}

That is qualitative, exploratory and descriptive research that aims to describe the situations experienced by nurses involved in the referring of a patient to the ICU by judicial decision. That is a project approved by Unisimos' ethics and research committee. It is verified that most of nurses are assuming their role as citizens; they are guiding families to seek support, and seek support in prosecutor aiming to become available an ICU bed.

Descriptors: Health Support, Hospitalization, Intensive Care Unit, Ethics.

\section{Encaminando el paciente critico para la UTI por decisión judicial: situaciones vivenciadas por los enfermeros}

Se trata de una investigación exploratória, cualitativa y descriptiva con el objetivo de describir lãs situaciones vivenciadas por los enfermeros(as) relacionadas al encaminamiento del paciente para hospitalización en UCI por la decisón judicial. Se trata de um proyecto aprovado por el comitê de ética e investigación de la Unisinos. Parece que los enfermeros, en su mayoría, están haciendo su parte a la ciudadanía, están impulsando a las familias a buscar ayuda, buscar la ayuda del fiscal a fin de hacer posible, al paciente critico, una cama en la UCl.

Descriptores: Asisténcia a la Salud, Hospitalización, Unidad de Cuidados Intensivos, La Ética.

\section{INTRODUÇÃO}

$\mathrm{P}$ aciente crítico ou gravíssimo é aquele que necessita de cuidados complexos e intensivos, monitoração contínua e assistência permanente, uma vez que há chances de descompensação hemodinâmica ${ }^{(1)}$. A Unidade de Terapia Intensiva (UTI) é o local idealizado para recebê-lo.

Segundo a Constituição Federal de 1988, artigo 196, a saúde é direito de todos e dever do Estado, garantida mediante políticas sociais e econômicas que visem à redução do risco de doença e de outros agravos e ao acesso universal e igualitário a ações e serviços para sua promoção, proteção e recuperação(2). Complementando, o artigo 197 diz que "são de relevância pública as ações e serviços de saúde, cabendo ao poder público dispor, nos termos da lei, sobre sua regulamentação, fiscalização e controle, devendo sua execução ser feita diretamente ou através de terceiros e, também, por pessoa física ou jurídica de direito privado"(2:11). Portanto, a saúde e/ou sua recuperação estão asseguradas de forma igualitária para todos os cidadãos, sendo uma obrigatoriedade do Estado e da União. Porém, quando não há disponibilidade de recursos por meio do Sistema Único de Saúde (SUS), é utilizado o serviço privado como alternativa, visando a garantir a recuperação da saúde e minimizar agravos. As políticas de saúde como a Vaga Zero, a criação da Regulação de Leitos do Estado e a internação por via judicial foram elaboradas com o propósito de auxiliar esse processo.

A deficiência no sistema de saúde e o consequente déficit de leitos em UTI não atendem à demanda, isto é, muitas vezes, existem pacientes graves na lista de espera por um leito na UTI que evoluem para um estágio de maior gravidade, tornando-se impossível a restauração da saúde. Essa situação provoca nos profissionais de saúde impotência e desconforto significativo, uma vez que enfrentam dificuldades para prestar uma assistência adequada (despreparo humano, área física inadequada e déficit de materiais e equipamentos essenciais para a preservação da

1 Enfermeira. Especialista em enfermagem em terapia intensiva pela Universidade do Vale do Rio dos Sinos (Unisinos) e Universidade Corporativa Hospital Mãe de Deus. Atua na UTI Hospital Regina/Novo Hamburgo e na Emergência do Hospital Municipal de Novo Hamburgo.

2 Enfermeira. Doutora em enfermagem pela Universidade Federal de Santa Catarina (UFSC). Professora adjunta da Unisinos. Membro do Grupo Práxis na UFSC. Coordenadora da especialização em enfermagem em terapia intensiva na Unisinos e Universidade Corporativa Hospital Mãe de Deus. E-mail: maraav@unisinos.br.

3 Enfermeira. Especialista de enfermagem em terapia intensiva pela Unisinos e Universidade Corporativa Hospital Mãe de Deus. Atua na UTI do Hospital Regina/Novo Hamburgo. 
vida). Nessa perspectiva, consideramos pertinente efetivar uma investigação que busque descrever as situações vivenciadas pelos enfermeiros frente ao encaminhamento de paciente para internação na UTI por decisão judicial.

\section{REVISÃO DA LITERATURA}

A crescente demanda por uma assistência cada vez mais complexa, sem o crescimento da oferta de serviço, aumenta os desafios para que a equidade seja concretizada, fornecendo acesso a uma assistência adequada, oportuna e de acordo com as necessidades da população. Uma das estratégias utilizadas no Brasil pelo SUS para otimizar o elo necessário entre a demanda existente e os recursos disponíveis e garantir o acesso aos serviços de saúde é a organização das centrais de regulação assistencial por temas ou áreas assistenciais ${ }^{(3)}$.

Essa proposta de Política Nacional de Regulação está focada em três eixos: a garantia da alocação de recursos para a implantação dos Complexos Reguladores da Assistência; o desenvolvimento de instrumentos que operacionalizem as funções reguladoras; e o desenvolvimento de um programa de capacitação permanente de recursos humanos(4).

O Rio Grande do Sul (RS), com o intuito de agilizar o atendimento, possui duas centrais reguladoras: a Central Metropolitana (CLM) tem sua concentração de trabalho na região metropolitana e a Central de Leitos do Estado (CLE), criada em junho de 2008, possui abrangência estadual ${ }^{(5)}$.

A central de internação realiza a mediação entre os hospitais disponíveis conforme a necessidade do doente. Para isso, conta com a utilização de um mapa de leitos onde estão centralizadas as informações pertinentes entre as vagas existentes, segundo a gravidade do doente e a infraestrutura necessária, considerando, também, a distância e o deslocamento entre o hospital de origem e a instituição receptora $^{(3)}$.

No RS, o transporte para esse evento é realizado pelo Samu. O processo ocorre a partir de um contato prévio entre a instituição que solicita o transporte e a central reguladora do Samu no momento em que é confirmado o leito ${ }^{(6)}$.

Outra política criada pelo poder governamental, a fim de garantir e efetivar a assistência à saúde de forma eficaz, é denominada Vaga Zero. Ela é definida como um leito obrigatoriamente disponibilizado em UTI, tanto em rede pública quanto em rede privada. Porém, essa obrigatoriedade acontece mediante parecer constitucional e geralmente é a instituição privada que deve aceitar o paciente. Caso a instituição descumpra o parecer, isso acarreta ofensa constitucional ${ }^{(5)}$.

Em suma, as internações por decisões judiciais ocorrem quando o município ou o estado não possui condições de garantir uma assistência adequada ao paciente grave ou gravíssimo em situações de urgência/emergência. Nessa circunstância, a família, ciente da gravidade de seu familiar e da necessidade de um leito em outro centro, recorre ao Ministério
Público (MP) ou a seu advogado para proceder ou deferir uma liminar, sendo essa uma ação contra o município e o estado encaminhada à CLE, buscando um leito de UTI' ${ }^{(5)}$.

\section{METODOLOGIA}

Pesquisa qualitativa, exploratória e descritiva. Os pesquisados constituem-se de dez enfermeiros que trabalham em diferentes instituições (privada ou pública) no contexto da emergência ou UTI, na região metropolitana de Porto Alegre. Realizamos entrevistas com um ou dois enfermeiros por instituição, com experiência mínima de seis meses. Os informantes serão aqui representados por I.1, I.2, I.3, ... O projeto foi aprovado em Comitê de Ética (parecer $n^{\circ}$ 004/2010/CEP/Unisinos) e os sujeitos manifestaram sua concordância por meio do Termo de Consentimento Livre e Esclarecido, conforme resolução 196/96. A coleta das informações foi realizada nos meses de março e abril de 2010, mediante entrevista individual, semiestruturada, gravada em fita cassete. A análise das informações segue o modelo de Minayo ${ }^{(7)}$.

\section{ANÁLISE DOS DADOS}

Conforme os relatos apresentados pelos enfermeiros que atuam em instituições públicas ou privadas, o cliente que consegue internação em UTI por decisão judicial é tanto aquele cuja família é ciente de seus direitos como cidadãos quanto aquele cuja família não tem qualquer tipo de esclarecimento prévio acerca do assunto. No caso desse último, basta que seja orientado pela equipe de saúde sobre a possibilidade de usar tal recurso para conseguir um leito em uma UTI. Foi relatado, ainda, o envolvimento político e divergências entre possuir ou não condições

financeiras por parte dos familiares.

Todos os enfermeiros entrevistados comentaram a importância dos profissionais de saúde em orientar as famílias quanto à existência desse recurso, que pode ser usado quando não se consegue um leito de UTI por métodos convencionais. Os profissionais aconselham os familiares a procurar a promotoria e o MP para que se consiga um leito de UTI. Além disso, informam os familiares quanto à gravidade do doente, bem como sobre a necessidade de buscar um leito de UTI e como fazer esse processo.

"Em meu ponto de vista, o que percebo é o fato de o profissional, e principalmente nós, enfermeiros, orientarmos o familiar de que há a necessidade de um leito em UTI. A Central de Leitos foi acionada e também ainda não conseguiu, e que ele pode, sim, porque está na Constituição Federal esse direito assegurado." (I. 5)

"Uma vez o familiar recebendo a mesma orientação, procurando a promotoria, um quadro grave, tendo risco de morte iminente, todos que eu já vi conseguem a vaga com a mesma brevidade, claro que tendo um leito disponível, indiferente da instituição ou da cidade." (I. 6)

A ética da saúde é, antes de tudo, a convicção de que a pessoa 
é a prioridade e que ela tem o direito de receber respostas claras e verídicas, conforme sua necessidade e compreensão. A ética da saúde exige reflexão permanente para tomar decisões ou praticar atos que possam interferir de modo adequado na integridade física e mental e no bem-estar da pessoa, ou seja, o objetivo principal é o respeito à dignidade humana ${ }^{(8)}$.

Nesse sentido, os enfermeiros sentem-se responsáveis por seus pacientes, não apenas por aplicar técnicas corretas ou identificar prioridades - são responsáveis pelas condutas que serão tomadas enquanto os pacientes estão impossibilitados de decidir o próprio tratamento. Os enfermeiros sentem-se como guardiões dos pacientes ${ }^{(9)}$.

Ainda, um dos papéis do MP é zelar para que os direitos constitucionais dos cidadãos sejam assegurados através de medidas judiciais ligadas ao atendimento de saúde e ao acesso a medicamentos e tratamentos especializados, enfim, a todos os recursos destinados à promoção, proteção e recuperação da saúde ${ }^{(10)}$.

As ações do MP vêm sendo divulgadas pela mídia, fazendo surgir no meio social a consciência de sua finalidade e importância e revelando os benefícios que sua atuação pode trazer à coletividade. É enfatizado que o promotor de justiça pode propor ações civis públicas, intervindo em processos visando ao interesse de incapazes em determinada situação ou em algum momento de sua vida. Desse modo, o promotor de justiça tem em mãos instrumentos capazes de auxiliar na busca do exercício pleno desse direito; bastaria, para isso, ser procurado pela parte interessada para que utilize um instrumento judicial ou extrajudicial em busca da situação almejada ${ }^{(10)}$.

Conforme os relatos dos entrevistados, a população que utiliza o serviço público nem sempre conhece a existência e a finalidade do MP e do promotor de justiça. Assim, há necessidade de os profissionais de saúde orientarem os familiares a procurar esse serviço, buscando a garantia de seus direitos. Nesse sentido, apresentamos alguns relatos indicando que, se as pessoas fossem mais esclarecidas, isso agilizaria o processo ou seria um dos fatores para a obtenção de um encaminhamento via decisão judicial.

"Observo que há familiares mais esclarecidos, que conhecem um pouco de lei ou conseguem algum contato com advogados. Infelizmente, os familiares mais humildes têm maior dificuldade de conseguir um leito de UTI." (I.7)

"Dos mais variados, mas a gente percebe que são geralmente os mais esclarecidos, que sabem seus direitos. Já os mais humildes muitas vezes se conformam mais e aceitam mais a situação." (I. 9)

Paradoxalmente, pode-se inferir que a grande população que precisa usar o SUS até sabe que tem direito à saúde, mas desconhece o modo para garantir esse direito, principalmente em situações de necessidade de atendimento específico e complexo, como é o caso da internação em um leito de UTI.
Os informantes sinalizam que as situações vivenciadas são diversas, porém a semelhança entre elas ocorre principalmente pela gravidade de cada caso, pela estrutura de cada instituição e pela ausência de leito de UTI. Discorrem sobre o mesmo impasse: a entrada do paciente na emergência; o diagnóstico da gravidade; e, devido à indisponibilidade de leito de UTI, o paciente é colocado na CLE e na CLM. Também foi apontada por todos, como fator determinante, a demora por parte de ambas as Centrais de Leitos em informar a disponibilidade de um leito de UTI para o paciente. A demora, além de gerar desconforto para a equipe de saúde devido a limitações para prestar uma assistência adequada, o que é verbalizado a seguir, também é geradora de estresse para a família do paciente que aguarda o leito.

"Temos uma demanda de pacientes graves maior do que a capacidade para atender e prestar uma assistência adequada. A gente coloca os pacientes na Central de Leitos, mas é difícil conseguir uma vaga. Temos na emergência um paciente que necessita de um leito em terapia intensiva, e o único recurso que temos é a transferência via ordem judicial." (I. 3)

"A gente percebe, pelo diagnóstico e pela necessidade de agilidade, que o tratamento deve ser iniciado. Por exemplo, um paciente infartado com supra ST no ECG e clínica para um infarto, você não pode ficar esperando de dois a três dias paraqueele receba o tratamento adequado para a revascularização." (I. 9)

O retardo no encaminhamento de um paciente com alguma gravidade aguda pode levá-lo à morte. Em casos de pacientes com trauma grave, o enfermeiro participa da previsão das necessidades da vítima, identificando prioridades, iniciando intervenções necessárias, estabilizando e reavaliando o estado desse paciente constantemente até o tratamento definitivo ${ }^{(11)}$.

Pode-se evidenciar que os enfermeiros são capazes de diferenciar as situações em que é vital o encaminhamento do paciente acometido por uma gravidade aguda para uma UTI. Conhecer a gravidade de cada paciente e, ao mesmo tempo, perceber a necessidade de um tratamento e monitoramento intensivo são fatores que podem desencadear o processo de orientação à família para que procure a promotoria, a fim de conseguir um leito de UTI e, assim, garantir a manutenção da vida do doente.

Segundo estudo realizado pela Associação de Medicina Intensiva Brasileira, Censo 2009, há no Brasil de um a três leitos de UTI para cada 10 mil habitantes, o que é recomendado pelo Ministério da Saúde. No RS, há 2,4\% de leitos para cada 10 mil habitantes, o que corresponde à média de um a três leitos de UTI para cada 10 mil habitantes. Porém, há estados brasileiros que estão abaixo dessa média. Esse mesmo estudo mostra que, das UTIs no Brasil, $39,5 \%$ são privadas, $33,5 \%$ são filantrópicas e $25,2 \%$ são públicas ${ }^{(12)}$.

Analisando por essa perspectiva, verificamos que estamos na média de leitos segundo a população, mas o que merece 
uma reflexão é a questão: desses de um a três leitos de UTI, quantos são localizados nas instituições privadas e quantos são destinados à rede pública, onde se concentra o maior número de usuários? Ainda considerando nosso estado, quantos municípios interioranos não possuem leito de UTI? Isso está expresso por um dos entrevistados.

"Na legislação, consta que, para uma determinada população, é necessário comportar uma UTI. Por exemplo, aqui em nosso município, de aproximadamente $50 \mathrm{mil}$ habitantes, seria necessário de quatro a cinco leitos de UTI, e não temos nenhum. $E$ isso não ocorre unicamente aqui, mas em outros hospitais de pequeno porte, e nessas situações é utilizada internação via judicial, principalmente quando a gente vê que a família é humilde e o paciente necessita de um cuidado intensivo." (I. 8)

Essa realidade se estendea outros municípios cujos moradores precisam ser removidos para cidades vizinhas a fim de serem internados em uma UTI. Por sua vez, a cidade que recebe e que tem em média de um a três leitos de UTI para seus habitantes se sobrecarrega ao ter de acolher pacientes de outras cidades para prestar uma assistência adequada.

Sabe-se que a reivindicação por mais leitos de UTI não é de hoje; é realizada pelos profissionais de saúde e pela sociedade. Logo, a gravidade dos pacientes que esperam um leito em UTI nas emergências exige que os profissionais de saúde tomem uma decisão precisa, que vai muito além da conduta e do manejo. Essa decisão abrange a sobrevida e evita sequelas no indivíduo.

"Recebemos um paciente jovem, com traumatismo cranioencefálico grave, com hematoma extradural. Nós não temos UTI aqui no hospital, não conseguimos leito de UTI em outro hospital, já que precisávamos de um bloco cirúrgico para procedimento cirúrgico com recuperação em UTI. Então, foi realizado um encaminhamento por ordem judicial." (I.8)

"Tivemos um paciente masculino, jovem, com aneurisma de aorta abdominal. Foi feito o atendimento inicial em hospital da região metropolitana, sem suporte cardiovascular, e depois encaminhado por ordem judicial para um centro de tratamento. Havia na emergência 12 pacientes graves aguardando leito de UTI." (I. 2)

Diante desses relatos, fica fácil entender por que ocorrem os encaminhamentos via decisão judicial. A falta de leitos de UTI também é assunto do MP, uma vez sabido que esse é um fator desencadeante para que ocorram mortes que poderiam ser evitadas. Em Fortaleza, o MP foi acionado para investigar mortes que ocorreram pela indisponibilidade de leito de UTI(10).

Com base nessas informações, percebe-se que o MP tem um importante papel em situações extremas, quando o direito à vida está comprometido e o cidadão é submetido a tratamento desumano e degradante. Cabe, então, ao MP assegurar os direitos do cidadão através de ações imediatas e precisas. Conforme o artigo 127 da Carta Magna, o MP é uma instituição permanente, essencial à função jurisdicional do Estado, sendo incumbido da defesa da ordem jurídica, do regime democrático e dos interesses sociais e individuais indisponíveis.

\section{CONCLUSÃO}

As situações vivenciadas por enfermeiros são as mais diversas, porém a semelhança entre elas é a gravidade de cada paciente e a instabilidade de cada caso, tornando imprescindível o encaminhamento do paciente para uma UTI. Verifica-se que os enfermeiros, em sua maioria, estão assumindo seu papel com cidadania e orientando os familiares a procurar ajuda e buscar auxílio junto ao MP, a fim de viabilizar ao paciente grave um leito de UTI.

A ausência de leito de UTI na rede pública é problema governamental, e o cidadão brasileiro não deve sofrer as consequências desse déficit, tampouco perder a vida pela indisponibilidade de leitos de UTI. Contudo, para que a população não seja penalizada por esse déficit, torna-se importante que os enfermeiros continuem orientando os familiares e que o Ministério Público atue juntamente com as instituições públicas.

\section{Referências}

1. Leite MA, Villa VCS. Dificuldades vivenciadas pela equipe multi na unidade de

terapia intensiva. Rev Latinoam Enferm. 2005;13(2):145-50.

2. Constituição da República Federativa do Brasil: Constituição 1988. $21^{a}$ ed.

São Paulo: Saraiva; 1998.

3. Evangelista PA, Barreto SM, Guerra HL. Central de regulação de leitos do SUS em

Belo Horizonte, Minas Gerais, Brasil: avaliação de seu papel estudo das internaçōes

por doenças isquêmicas do coração. Cad Saúde Pública. 2008;24(4):767-76.

4. Conselho Nacional de Secretários de Saúde (BR). Regulação em Saúde. Brasilia:

Conass; 2007.

5. Santos JB. “Vaga zero em caso de emergência”. Folha Universal. 2009 Jun 28:8-11.

6. Serviço Médico de Atendimento de Urgência. Transferência Inter-hospitalar

de pacientes graves [Internet]. [citado em 2010 Mai 25].

Disponível em: http://www.samu.saude.gov.rs

7. Minayo MCS. O desafio do conhecimento: pesquisa qualitativa em saúde. $8^{a}$ ed.

São Paulo: Hucitec; 2004.
8. Dallari SG. Ética sanitária. In: Aranha MI, Tojal SBB, organizadores.

Curso de Especialização a Distância em Direito Sanitário para Membros do Ministério Público e da Magistratura Federal. Brasília: Faculdade de Direito da UnB, Ministério da Saúde; 2001. p. 119-40.

9. Vargas MAO, Ramos FRS. Responsabilidade no cuidar: ou do tempo que nos toca viver como enfermeiros/as intensivistas. Rev Esc Enferm USP. 2010 Reeusp-721. (no prelo).

10. Ribeiro EDC. Saúde como um direito: as inter-relações da auditoria em saúde com o Ministério Público na garantia da integralidade da atençăo [dissertaçāo]. Fortaleza: Universidade Estadual do Ceará; 2005.

11. Thomaz RR, Lima FV. Atuação do enfermeiro no atendimento pré-hospitalar na cidade de São Paulo. Acta Paul Enferm. 2000;13(3):59-65.

12. Associaçẫo de Medicina Intensiva Brasileira. Censo divulga realidade das UTI brasileiras [Internet]. [citado em 2010 Mai 20]. Disponivel em: http://noticias.r7.com/ saude/noticia/censo. 